\title{
Mycobacterium tuberculosis kompleks izolatlarında birinci basamak anti-tüberküloz ilaçlara direnç trendleri: Türkiye'den üçüncü basamak bir hastane çalışması
}

\author{
Hatice YAZISIZ ${ }^{1}$ \\ Derya HIRÇIN CENGER ${ }^{2}$ \\ Veli YAZISIZ ${ }^{3}$ \\ Lütfiye KILIÇ ${ }^{4}$ \\ Sedat ALTIN ${ }^{4}$
}

${ }^{1}$ Department of Medical Microbiology, Faculty of Medicine, Akdeniz University, Antalya, Turkey

${ }^{1}$ Akdeniz Üniversitesi Tıp Fakültesi, Tıbbi Mikrobiyoloji Anabilim Dalı, Antalya, Türkiye

${ }^{2}$ Clinic of Infectious Diseases and Clinical Microbiology, Istanbul Yedikule Chest Diseases and Chest Surgery Training and Research Hospital, Istanbul, Turkey

2 İstanbul Yedikule Göğüs Hastalıkları ve Göğüs Cerrahisi Eğitim ve Araştırma Hastanesi, İnfeksiyon Hastalıkları ve Klinik Mikrobiyoloji Kliniği, İstanbul, Türkiye

${ }^{3}$ Division of Rheumatology, Department of Internal Diseases, Faculty of Medicine, Akdeniz University, Antalya, Turkey

${ }^{3}$ Akdeniz Üniversitesi Tıp Fakültesi, İç Hastalıkları Anabilim Dalı, Romatoloji Bilim Dalı, Antalya, Türkiye

${ }^{4}$ Clinic of Chest Diseases, Istanbul Yedikule Chest Diseases and Chest Surgery Training and Research Hospital, Istanbul, Turkey

4 İstanbul Yedikule Göğüs Hastalıkları ve Göğüs Cerrahisi Eğitim ve Araştırma Hastanesi, Göğüs Hastalıkları Kliniği, İstanbul, Türkiye

Makale atıfi: Yazısız H, Hırçın Cenger D, Yazısız V, Kılliç L, Altın S. Mycobacterium tuberculosis kompleks izolatlarında birinci basamak anti-tüberküloz ilaçlara direnç trendleri: Türkiye'den üçüncü basamak bir hastane çalışması. Tuberk Toraks 2019;67(2):92-101.

\section{Yazışma Adresi (Address for Correspondence)}

Dr. Hatice YAZISIZ

Akdeniz Üniversitesi Tıp Fakültesi,

Tıbbi Mikrobiyoloji Anabilim Dalı,

ANTALYA-TÜRKIYE

e-mail: drhyazisiz@yahoo.com.tr

CTelif Hakkı 2019 Tüberküloz ve Toraks. Makale metnin www.tuberktoraks.org web adresinden ulaşılabilir.
ÖZET

Mycobacterium tuberculosis kompleks izolatlarında birinci basamak anti-tüberküloz ilaçlara direnç trendleri: Türkiye'den üçüncü basamak bir hastane çalışması

Giriş: Tüberküloz (TB) az gelişmiş ülkeler için önemli bir halk sağlığı problemi olmaya devam eden bir hastalıktır. TB'nin etkin tedavisi ve kontrolü için ilaç duyarlıık oranları izlenmelidir. Bu çalışmanın amacı Mycobacterium tuberculosis kompleks suşlarında birinci basamak anti-TB ilaçlara karşı gelişen direnç oranlarını belirlemektir.

Materyal ve Metod: Bir yıllık dönemde Yedikule Gögüs Hastalıkları ve Gögüs Cerrahisi Eğitim ve Araştırma Hastanesi Mikrobiyoloji Laboratuvarı'nda izole edilen 974 hastaya ait 1193 örnekte M. tuberculosis kompleks izole edilmiştir. Örneklerin çoğunluğu balgamdır ( $n=897, \% 92.1)$. Anti-TB ilaç duyarlılık testleri Mycobacterium Growth Indicator Tube 960 sistemiyle yapılmıştır. 
Bulgular: iki yüz altmış (\%26.7) izolatta test edilen dört birinci basamak anti-TB ilaçtan en az birine direnç vardır. İoniazid direnci 197 (\% 20.2) izolatta, rifampisin direnci 82 (\% 8.4), etambutol direnci 63 (\% 6.5) ve streptomisin direnci 140 (\% 14.4) izolatta vardır. İzoniazid direnci olan 197 izolatın 89'unda tekli izoniazid direnci (\% 45.2) varken diğer anti-TB ilaçlarda tekli ilaç direnci rifampisin için \% 15.9 ( $n=13)$, etambutol için \%7.9 $(n=5)$ ve streptomisin için \%30.7 $(n=43)$ bulundu. Kırk sekiz (\% 4.9) izolatta ikili, 22 (\%2.3) üçlü, 42 (\%4.3) dörtlü ilaç direnci vardır. Çoklu ilaç direnci olan izolat sayısı $68(\% 7.0)$ idi. TB ilaçlarına direnç sıklı̆̆ı ile cinsiyet ve yaş arasında ilişki olmadığı görüldü. Bu çalışmanın sonuçları ile 1998-2003, 2004-2007 ve $2008-2010$ yılları arasındaki Türkiye'den bildirilen anti-TB ilaç direnç oranlarıla birlikte değerlendirildiğinde izoniazid ve streptomisin dirençlerinin artma eğiliminde olduğu görüldü.

Sonuç: Ilaç duyarlıık test sonuçlarının takibinin TB tedavisinin yönetimine ve tedavi başarısının arttırılmasına katkı sağlayabilir. Türkiye'de izoniazid ve streptomisin dirençlerinin artma eğilimindedir. Anti-TB ilaçlara direnç gelişimini etkileyen bölgesel ve global faktörleri araştıran daha fazla klinik çalışmalara ihtiyaç vardır.

Anahtar kelimeler: Tüberküloz; ilaç direnci; ilaç duyarlılık testi; izoniazid; rifampisin; streptomisin; etambutol

\section{SUMMARY}

First-line anti-tuberculosis drug resistance trends of Mycobacterium tuberculosis complex isolates. A tertiary hospital study in Turkey

Introduction: Tuberculosis (TB) is continuing to be a important public health problem in the undeveloped countries. Drug sensitivity rate should be monitored for the effective treatment and control in the TB. The aim of this study was to determine the rate of resistance to first line TB drugs in the Mycobacterium tuberculosis complex isolates.

Materials and Methods: During one-year period, M. tuberculosis complex was isolated in the 1193 samples from 974 patients in the Mycobacterial Laboratory of Yedikule Chest Diseases and Chest Surgery Education and Research Hospital, Istanbul, Turkey. The majority of samples isolated in the M. tuberculosis complex were sputum ( $n=897,92.1 \%)$. Anti-TB drug susceptibility testing was performed with Mycobacterium Growth Indicator Tube 960 system.

Results: Two hundred and sixty isolat $(26.7 \%)$ were resistant to at least one of the four first-line anti-TB drugs tested. One hundred ninety seven isolates were resistances to isoniazid (20.2\%); 82 to rifampin (8.4\%), 63 to ethambutol (6.5\%) and 140 to streptomycin $(14.4 \%)$. Of the 197 isoniazid-resistant isolates, $89(45.2 \%)$ isolates was only isoniazid-resistance, only rifampin-resistance were found $15.9 \%(n=13)$, ethambutol $7.9 \%(n=5)$ and streptomycin $30.7 \%(n=43)$. There were $48(4.9 \%)$ isolates with two drugresistance, $22(2.3 \%)$ isolates with three drug-resistance, and $42(4.3 \%)$ isolates with four drug-resistance. The multidrug resistance rate was 7\% (68 of 974). There was no relationship with between the frequency of TB drug resistance and gender or age. The isoniazid--resistance and streptomycin-resistance were seen to tend to increase if together considered the results of this study with outcomes of previously reported studies from Turkey in the 1998-2003, 2004-2007 and 2008-2010 years.

Conclusion: Monitoring of drug susceptibility test results can contribute to the management of TB treatment and increase treatment success. Isoniazid-resistance and streptomycin-resistance tend to increase in Turkey. Further clinical studies are needed to investigate regional and global factors affecting the development of resistance to first-line TB drugs.

Key words: Tuberculosis; drug resistance; drug susceptibility test; isoniazid; rifampin; streptomycin; ethambutol

\section{Giriş}

Tüberküloz (TB) halen her yıl milyonlarca insanda hastalık yapan ve en çok ölüme neden olan 10 infeksiyon hastalığından biridir. Dünya Să̆lık Örgütü (DSÖ) 2018 raporuna göre 2017 yılında yaklaşık 1.3 milyon kişi TB'den ölmüştür (1). TB tüm dünyada olduğu gibi Türkiye'de de önemli bir halk sağlığı sorunu olmaya devam etmektedir. Türkiye'de 2016 yılı tahmini TB insidans hızı \%18 ve tahmini mortalite hızı yüz binde 0.62 bildirilmiş̧ir (2).

TB tedavisinin ilk basamağında kullanılan ilaçlar izoniazid $(H)$, rifampisin $(R)$, etambutol (E), streptomisin (S) ve pirazinamiddir. Bu ilaçlara karşı gelişen direnç, TB'de mortaliteyi belirleyen en önemli unsurlardan biridir $(1,3)$. Anti-TB ilaçlara karşı gelişen direnç oranlarının yıllar içinde ve ülkeden ülkeye farklılık gösterdiği bilinmektedir. T.C Sağlık Bakanlığı 2018
Verem Savaş Raporunda (VSR) Türkiye'deki verem savaş dispanserleri kayıtlarına göre kültürde üreme olan hastaların \%19.2'sinde en az bir ilaca direnç vardır. En yüksek oranda direnç $\mathrm{H}^{\prime}$ ye karşıdır (\%11.9) ve çoklu ilaca dirençli tüberküloz (ÇiD-TB) oranı \%3.3'tür. Önceden tedavi görmüş hastalarda ilaç dirençleri yeni tanı alan hastalardan daha fazladır (2). Türkiye'den yayınlanan hastane bazlı araştırmalarda ise anti-TB ilaç direnç oranları daha yüksektir (4-9).

Tüberküloz ilaçlarına karşı gelişen direnç oranlarının sürekli izlenmesi, yıllar içindeki değişiminin monitorize edilmesi ve laboratuvar sonuçlarının klinik ile uyumunun araştırılması TB ile mücadelede başarıya ulaşmak için gereklidir. Literatür tarandığında, Türkiye'den üçüncü basamak hastanelerden bildirilmiş anti-TB ilaç direnç oranları 2011 yılı ve öncesine aittir. Yedikule Göğüs Hastalıkları ve Gögüs Cerrahisi Eğitim 
ve Araşıırma Hastanesi, Türkiye'nin en çok TB tanısı konulan ve tedavisi yapılan hastanelerinden biridir. TB araştırması için mikrobiyoloji laboratuvarına gönderilen örneklerin sonuçları ve anti-TB ilaç direnç oranları daha önceki yıllarda yayınlanmıştır $(6,7)$. Bu çalışma önceki çalışmaların devamı niteliğinde olup amacı laboratuvarda Mycobacterium tuberculosis kompleks izole edilen örneklerde anti-TB ilaç direnç oranlarını belirlemek, aynı laboratuvarın önceki verileri ve Türkiye'nin diğer TB laboratuvarlarından bildirilen ilaç direnç oranlarıyla karşılaştırmaktır.

\section{MATERYAL ve METOD}

\section{Hasta Verileri ve Çalışma Örnekleri}

Çalışmaya 12 aylık dönemde (1 Ekim 2011-30 Eylül 2012) Yedikule Göğüs Hastalıkları ve Göğüs Cerrahisi Eğitim ve Araştırma Hastanesi Mikrobiyoloji Laboratuvarına TB araştııılması amacıyla gönderilen örnekler dahil edildi. Çalışmanın yapıldığı dönemde bu TB laboratuvarının dış kalite kontrolleri Türkiye'de TB tanısı için referans merkez olan Refik Saydam Tüberküloz ve Araştırma Laboratuvarı tarafından yapilıyordu.

$\mathrm{Bu}$ çalışmanın verileri hastane kayıt sisteminden retrospektif olarak elde edildi. Çalışmanın yapıldığı dönemde 974 hastaya ait 1193 örnekte M. tuberculosis kompleks izole edildiği ve birinci basamak anti-TB ilaçlara karşı duyarlııık testlerinin yapıldığı görüldü. Birden fazla izolatı olan hastalarda ilk kültür ve ilaç duyarlıık sonuçları değerlendirmeye alındı.

\section{İzolatların İdentifikasyonu ve ilaç Direnç Çalışmaları}

TB araştırılması için laboratuvara kabul edilen tüm örnekler homojenizasyon-dekontaminasyon işlemi tabi tutuldu. Bu işlem için $\mathrm{NaOH}-\mathrm{NALC}$ içeren kullanıma hazır kit, Mycoprosafe (SALUBRIS kit, Kubica) kullanıldı. N-acetyl-L-cysteine içeren tüplere maksimum $10 \mathrm{~mL}$ olacak şekilde gönderilen örneklerden eklendi. Aynı miktarda sodyum hidroksitsodyum sitrat çözeltisinden ilave edildi. Bir vorteks ile karıştırma işleminden sonra oda ısısında 15 dakika bekletildi. Fosfat tamponu ilavesi sonrası 2000 devirde 15 dakika santrifüj edildi. Süpernatant uzaklaştırıldı, önerilen oranda tekrar fosfat tamponu eklendi. Sediment vorteksle tekrar karıştırıldıktan sonra $500 \mu \mathrm{L}$ süspansiyon Löwenstein-Jensen (LJ) medium ve Mycobacterium Growth Indicator Tube (MGIT) 960 tüplerine alınarak inkübasyona bırakıldı. İdrar örneklerinde konsantrasyon için $50 \mathrm{~mL}$ örnek tüplere alındı, 2000x devirde 15 dakika santrifüj edildikten sonra süpernatant uzaklaştırıldı sonra hidroksitsodyum sitrat çözeltisinden ilave edildi. Bu aşamadan sonraki süreçler diğer klinik örneklerle aynı şekilde ilerledi.

LJ medium (Salubris Inc., Istanbul) 8 hafta boyunca $37^{\circ} \mathrm{C}$ inkübe edildi ve haftalık olarak kontrol edildi. MGIT 960 tüpleri, MGIT 960 sisteminde (BACTEC MGIT 960 system, Becton Dickinson) inkübe edildi. MGIT 960 sistemi üreme olması halinde otomatik olarak uyarı veren bir sistemdir. Hem LJ hem de MGIT 960 sisteminde üreme saptanan bütün örneklerden Aside-Rezistan Basil incelemesi için mikroskopik yayma yapılarak pozitiflik doğrulandı. M. tuberculosis kompleksi diğer TB dışı Mycobacterium türlerinden ayırmak için para-nitrobenzoik asit kiti kullanıldı; Para-nitrobenzoik asit tüpündeki büyümenin inhibisyonu M. tuberculosis kompleks varlığını, büyümenin devam etmesi ise TB dışı Mycobacterium türlerini işaret ediyordu.

M. tuberculosis kompleks izole edilen izolatlarda $\mathrm{H}$, $\mathrm{R}, \mathrm{E}$ ve $\mathrm{S}$ için duyarlııı testleri yapıldı. ilaç duyarlılıklarını tespiti için BD MGIT 960 sistemi kullanıldı. Antimikobakteriyal duyarlılık testi için geliştirilen BACTEC MGIT 960 SIRE kiti kültürde üreyen $M$. tuberculosis için kullanılan nonradyometrik bir duyarlılık testidir (10). Bu kit 4-13 günde sonuç veren kalitatif bir testtir. M. tuberculosis kompleks izolatında ilaçlı ve ilaçsız tüpün üremesinin karşılaştırılması esasına dayanır. Kitin kullanım klavuzuna göre ilaç direnci $0.1 \mu \mathrm{g} / \mathrm{mL} \mathrm{H}, 1 \mu \mathrm{g} / \mathrm{mL} \mathrm{R}$, $1 \mu \mathrm{g} / \mathrm{mL}$ S ve $5 \mu \mathrm{g} / \mathrm{mL}$ E ortamında $\% 1$ 'den daha fazla büyüme olarak kabul edilir (10). Kitin kullanım talimatına uygun olarak çalışılan testler otomatik olarak yorumlanır. Tek ilaç direnci, herhangi bir ilaca karşı direnç; ÇiD-TB ise en az $\mathrm{H}$ ve $\mathrm{R}$ kombinasyonuna karşı olan direnç olarak kabul edildi.

\section{Literatür Tarama}

Pubmed veri tabanında "tüberculosis", "Mycobacterium tuberculosis", "drug susceptibility", "drug-resistance", "isoniazid", "rifampin", "streptomycin", "ethambutol" ve "Turkey" anahtar kelimeleri ile taramalar yapılarak Türkiye'den yapılmış ve SCI/SCI-Expanded dergilerde yayınlanmış araştırma makalelerine ulaşıldı. Son 20 yıl içinde Türkiye'den yayınlanmış anti-TB ilaç direnç çalışmaları tarandı. Analiz için yeterli dataları içeren makalelerden elde edilen verilere göre yıllara göre Türkiye'deki ilaç direnç oranlarının değişimi hesaplandı. 


\section{Etik Kurul Onayı}

Bu çalışma Yedikule Göğüs Hastalıkları ve Göğüs Cerrahisi Eğitim ve Araştırma Hastanesi Etik Kurulu tarafından onaylanmıştır.

\section{İstatistiksel Analiz}

ìstatistiksel analizler Windows SPSS 13.0 program (SPSS Inc., Chicago, IL, USA) kullanılarak yapıldı. Örneklerin tanımlanması ve sonuçların değerlendirilmesi için tanımlayıcı istatistikler kullanıldı. Tüm numerik veriler sıklık ve yüzde olarak ifade edildi. Kategorik veriler ki-kare testi, sayısal veriler student t-testi ile karşılaşıııılı. İstatistiksel anlamlılık için p değeri < 0.05 kabul edildi.

\section{BULGULAR}

Çalışma süresi olarak belirlenen bir yıllık dönemde TB araştırılması için laboratuvara örnekleri gönderilen, M. tuberculosis kompleks izole edilen ve birinci basamak anti-TB ilaçlar için duyarlılık testleri yapılan, 974 hastanın verileri analiz edildi. Hastaların $726(\% 74.5)$ 'sı erkek, 248 (\%25.5)'i kadın, ortalama yaş $39.1 \pm 16.8$ yıldı. M. tuberculosis kompleks izole edilen örneklerin çoğunluğu balgam ( $\mathrm{n}=897, \%$ 92.1), daha az sayıda diğer vücut sıvılarından [63 bronkoalveolar lavaj sıvıSı (\%6.5), 7 plevral sıvı (\%0.7), 7 diğer] oluşmaktaydı.

M. tuberculosis kompleks için anti-TB ilaç direnci çalışılan 974 izolatın $260(\% 26.7)^{\prime}$ ında en az bir antiTB ajana direnç vardı. H direnci 197 (\%20.2) izolatta, $\mathrm{R}$ direnci $82(\% 8.4)$, E direnci $63(\% 6.5)$ ve $\mathrm{S}$ direnci 140 (\%14.4) izolatta vardı. H direnci olan 197 izolatın 89'unda tekli $\mathrm{H}$ direnci (\%45.2) varken diğer anti-TB ilaçlarda tekli ilaç direnci oranları R için \%15.9 (n= $13)$, E için $\% 7.9(n=5)$ ve $S$ için $\% 30.7(n=43)$ bulundu. Kırk sekiz (\%4.9) izolatta ikili, $22(\% 2.3)$ izolatta ise üçlü ilaç direnci vardı. ÇiD-TB olan izolat sayısı 68 (\%7.0) bulundu. M. tuberculosis kompleks birinci basamak tedavisinde kullanılan dört anti-TB ajana dirençli olan izolat sayısı $42(\% 4.3)$ idi. Tablo 1'de anti-TB ilaçlara dirençli izolat sayıları ve oranları ayrıntılı olarak verilmiştir. Şekil 1'de ise tekli ve çoklu ilaç dirençlerinin dağılımı grafik olarak gösterilmiş̧ir.

Anti-TB ilaç dirençlerine cinsiyetin etkisini belirlemek için yapılan karşılaştırmalarda en az bir anti-TB ajana veya ilaçlara $(H, R, E$ ve $S)$ tekli direnç oranları açısından cinsiyetler arasında fark yoktu ( $p>0.05)$. Tüm antiTB ilaçlara duyarlı hastaların yaş ortalaması $39.4 \pm$ 16.9 yıl, en az bir anti-TB ilaçlara direnci olanların

Tablo 1. Anti-tüberküloz ilaç duyarıılık test sonuçlarının dağılımı

\begin{tabular}{|c|c|c|c|}
\hline & $\mathbf{n}$ & $\begin{array}{l}\text { Anti-TB ilaç duyarlılı̆̆ çalışılan izolat } \\
(n=974)\end{array}$ & $\begin{array}{l}\text { En az bir anti-TB ilaç direnci saptanan izolat } \\
\qquad(n=260)\end{array}$ \\
\hline İzoniazid (H) & 197 & $\% 20.2$ & $\% 75.0$ \\
\hline Rifampisin (R) & 82 & $\% 8.4$ & $\% 31.5$ \\
\hline Etambutol (E) & 63 & $\% 6.5$ & $\% 24.2$ \\
\hline Streptomisin (S) & 140 & $\% 14.4$ & $\% 53.8$ \\
\hline Tekli ilaç direnci & 148 & $\% 15.2$ & $\% 56.9$ \\
\hline $\mathrm{H}$ & 89 & $\% 9.1$ & $\% 34.2$ \\
\hline $\mathrm{R}$ & 13 & $\% 1.3$ & $\% 5.0$ \\
\hline $\mathrm{E}$ & 5 & $\% 0.5$ & $\% 1.9$ \\
\hline $\mathrm{S}$ & 43 & $\% 4.4$ & $\% 16.5$ \\
\hline İki ilaca direnç & 48 & $\% 4.9$ & $\% 18.4$ \\
\hline $\mathrm{HR}$ & 7 & $\% 0.7$ & $\% 2.7$ \\
\hline $\mathrm{HE}$ & 6 & $\% 6.1$ & $\% 2.3$ \\
\hline $\mathrm{HS}$ & 32 & $\% 3.3$ & $\% 12.3$ \\
\hline RE & 1 & $\% 0.1$ & $\% 0.4$ \\
\hline RS & 0 & - & - \\
\hline ES & 4 & $\% 0.4$ & $\% 1.5$ \\
\hline Üç ilaca direnç & 22 & $\% 2.3$ & $\% 8.5$ \\
\hline HRE & 3 & $\% 0.3$ & $\% 1.1$ \\
\hline HRS & 16 & $\% 1.6$ & $\% 6.2$ \\
\hline HSE & 3 & $\% 0.3$ & $\% 1.1$ \\
\hline RES & 0 & - & - \\
\hline Dört ilaca direnç (HRSE) & 42 & $\% 4.3$ & $\% 16.2$ \\
\hline
\end{tabular}




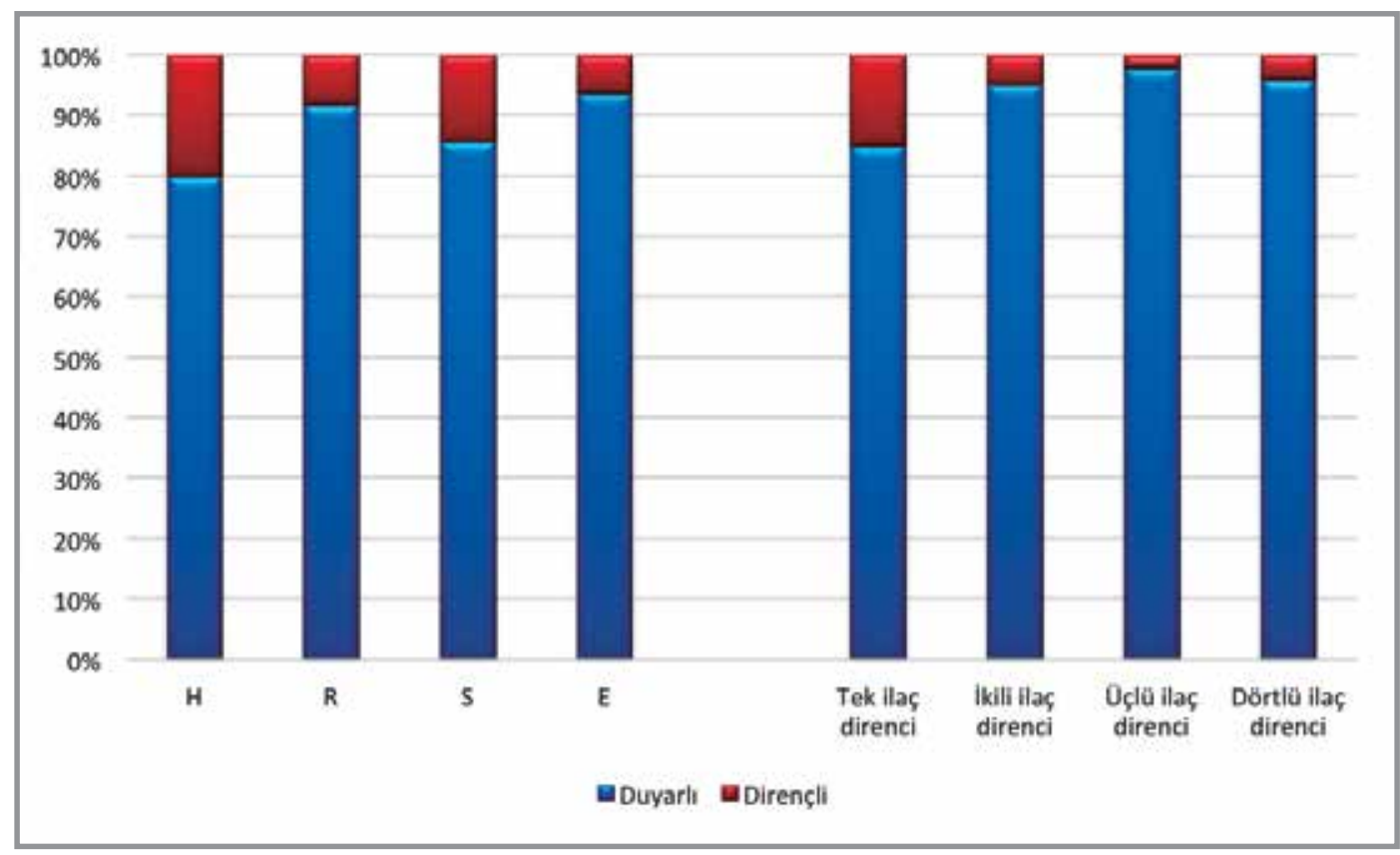

Şekil 1. Anti-tüberküloz ilaçlara duyarlılık dağılımları.

H: İzoniazid, R: Rifampisin, E: Etambutol, S: Streptomisin.

Tablo 2. Yaş gruplarına göre anti-tüberküloz ilaç direnci olan izolatların dağılımı

\begin{tabular}{|c|c|c|c|c|c|c|c|c|c|c|c|c|c|c|c|c|c|c|}
\hline \multirow[b]{2}{*}{ Yaş aralığı } & \multicolumn{2}{|c|}{$\begin{array}{l}\text { En az bir } \\
\text { ilaç direnci }\end{array}$} & \multicolumn{2}{|c|}{ İzoniazid } & \multicolumn{2}{|c|}{ Rifampisin } & \multicolumn{2}{|c|}{ Etambutol } & \multicolumn{2}{|c|}{ Streptomisin } & \multicolumn{2}{|c|}{ ÇiD-TB } & \multicolumn{2}{|c|}{$\begin{array}{l}\text { İkili ilaç } \\
\text { direnci }\end{array}$} & \multicolumn{2}{|c|}{$\begin{array}{l}\text { Üçlü ilaç } \\
\text { direnci }\end{array}$} & \multicolumn{2}{|c|}{$\begin{array}{l}\text { Dörtlü ilaç } \\
\text { direnci }\end{array}$} \\
\hline & n & $\%$ & $n$ & $\%$ & $n$ & $\%$ & $n$ & $\%$ & $n$ & $\%$ & $\mathrm{n}$ & $\%$ & $\mathbf{n}$ & $\%$ & $\mathrm{n}$ & $\%$ & $n$ & $\%$ \\
\hline$\leq 15(n=13)^{\&}$ & 1 & 7.7 & 1 & 7.7 & 1 & 7.7 & 1 & 7.7 & 1 & 7.7 & 1 & 7.7 & 0 & - & 0 & - & 1 & 7.7 \\
\hline $15-24(n=183)$ & 55 & 30.0 & 38 & 20.7 & 15 & 8.1 & 9 & 4.9 & 29 & 15.8 & 12 & 6.6 & 9 & 4.9 & 9 & 4.9 & 3 & 1.6 \\
\hline $25-34(n=243)$ & 62 & 25.5 & 50 & 20.6 & 18 & 7.4 & 15 & 6.2 & 36 & 14.8 & 16 & 6.6 & 14 & 5.8 & 4 & 1.6 & 11 & 4.5 \\
\hline $35-44(n=155)$ & 39 & 25.2 & 28 & 18.1 & 15 & 9.8 & 11 & 7.1 & 23 & 14.8 & 11 & 7.1 & 6 & 3.9 & 2 & 1.2 & 9 & 5.8 \\
\hline $45-54(n=137)$ & 39 & 28.5 & 33 & 24.0 & 13 & 9.5 & 9 & 6.6 & 17 & 12.4 & 11 & 8.1 & 10 & 7.3 & 2 & 1.5 & 6 & 4.4 \\
\hline$\geq 55(n=179)$ & 44 & 24.6 & 30 & 16.6 & 14 & 7.8 & 13 & 7.3 & 24 & 13.4 & 13 & 7.3 & 5 & 2.8 & 4 & 2.3 & 8 & 4.5 \\
\hline $\mathrm{p}$ & \multicolumn{2}{|c|}{0.489} & \multicolumn{2}{|c|}{0.504} & \multicolumn{2}{|c|}{0.967} & \multicolumn{2}{|c|}{0.955} & \multicolumn{2}{|c|}{0.921} & \multicolumn{2}{|c|}{0.968} & \multicolumn{2}{|c|}{0.765} & \multicolumn{2}{|c|}{0.567} & \multicolumn{2}{|c|}{0.345} \\
\hline
\end{tabular}

$38.5 \pm 16.2$ yıl bulundu, fark istatistiksel olarak anlamIı değildi $(p=0.514)$. Hastalar yaş gruplarına göre sınıflandırıldığında hem tek ilaç hem de çoklu ilaç dirençleri açısından yaşın önemli olmadığı görüldü (Tablo 2).

Literatür taraması ile 1998-2012 yıllarını kapsayan dönemde on dokuz çalışmanın yayınlandığı tespit edildi (4-9,11-23). Bu çalışmaların yapıldığı bölge, yıl, izolat sayıları ve anti-TB ilaç direnç oranları Tablo 3'te gösterilmiştir. İzolat sayısı, çalışmanın yapıldığı dönem ve ilaç duyarlılık test sonuçlarına bakılarak değerlendirme yapıldı. illaç duyarlılık testlerinin kapsadığı dönemlere göre 1998-2003, 2004-2007 ve 20082010 yılları arasındaki anti-TB ilaç direnç oranları tekrar hesaplandı ve bizim çalışmamızın sonuçlarıyla birlikte değerlendirildi. Tablo 4 ve Şekil 2'de bu çalışmalardan elde edilen verilere göre yıllar içinde en az bir anti-TB ilaca direnç ile $H, R, S$ ve $E$ için hesaplanan direnç oranları ayrıntılı olarak sunulmuştur.

\section{TARTIŞMA}

TB ilaçlarına direncin artması ve ÇiD-TB gelişimi global TB kontrolünü sağlamada karşılaşılan en önemli zorluklardan biridir (1). ÇiD-TB olan hastaların tedavisi zordur ve birinci basamak tedavide yer alan ilaçlardan 


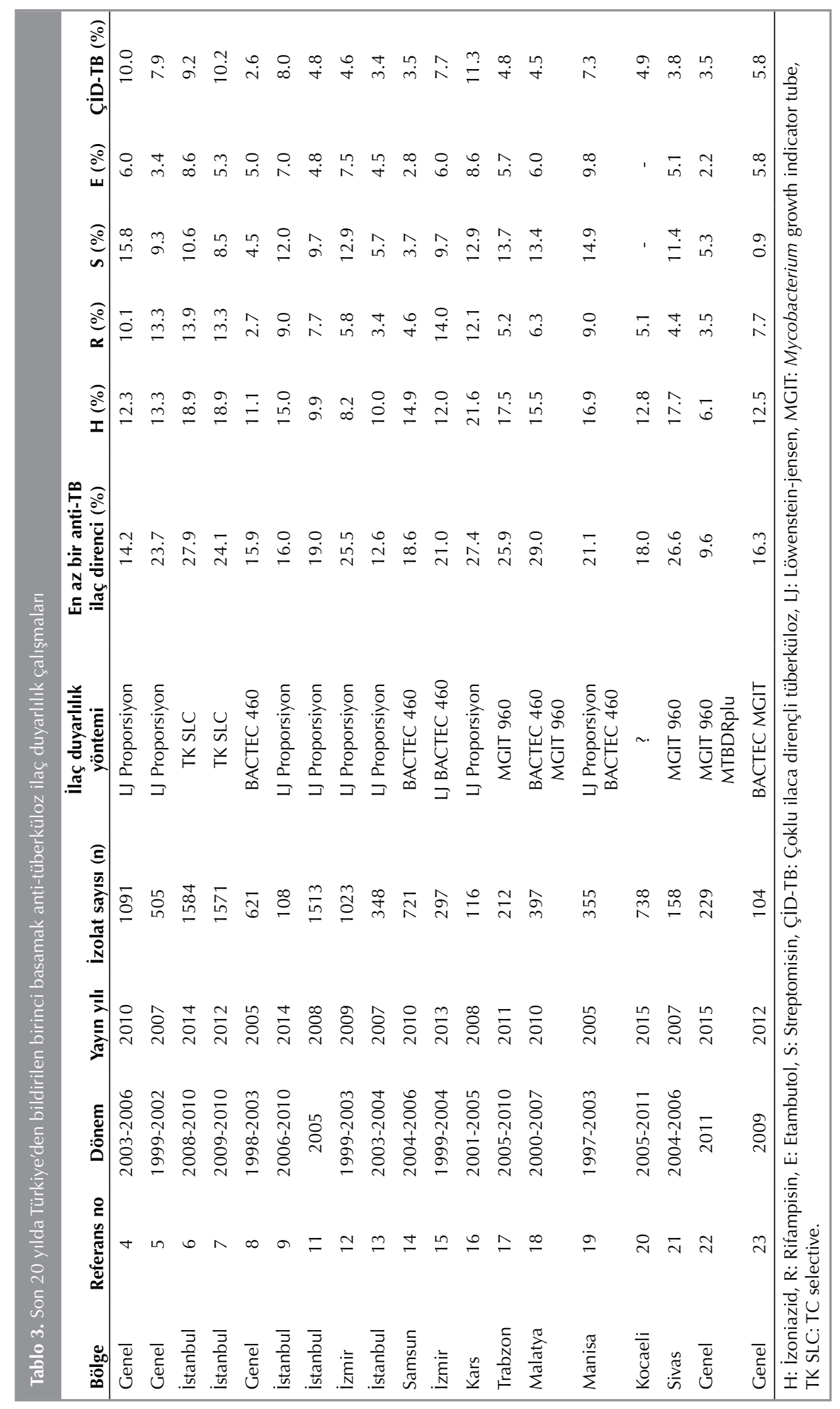


Mycobacterium tuberculosis kompleks izolatlarında birinci basamak anti-tüberküloz ilaçlara direnç trendleri: Türkiye'den üçüncü basamak bir hastane çalışması

Tablo 4. Yıllara göre Türkiye'den bildirilen anti-tüberküloz ilaç dirençlerinin oranları

\begin{tabular}{|c|c|c|c|c|c|c|c|c|}
\hline & \multicolumn{2}{|c|}{$\begin{array}{c}1998-2003^{*} \\
(n=2799)\end{array}$} & \multicolumn{2}{|c|}{$\begin{array}{c}2004-2007^{* *} \\
(\mathbf{n}=\mathbf{4 6 2 5})\end{array}$} & \multicolumn{2}{|c|}{$\begin{array}{c}2008-2010^{\#} \\
(n=3298)\end{array}$} & \multicolumn{2}{|c|}{$\begin{array}{c}2011-2012^{\# \#} \\
(n=974)\end{array}$} \\
\hline & $\mathrm{n}$ & $\%$ & $\mathrm{n}$ & $\%$ & $\mathrm{n}$ & $\%$ & $\mathrm{n}$ & $\%$ \\
\hline En az bir ilaç dirençli & 621 & 22.2 & 986 & 21.3 & 843 & 25.6 & 260 & 26.7 \\
\hline İzoniazid & 318 & 11.4 & 590 & 12.8 & 606 & 18.4 & 197 & 20.2 \\
\hline Rifampisin & 220 & 7.9 & 330 & 7.1 & 437 & 13.2 & 82 & 8.4 \\
\hline Etambutol & 179 & 6.4 & 227 & 4.9 & 226 & 6.8 & 63 & 6.5 \\
\hline Streptomisin & 288 & 10.3 & 481 & 10.4 & 302 & 9.2 & 140 & 14.4 \\
\hline
\end{tabular}

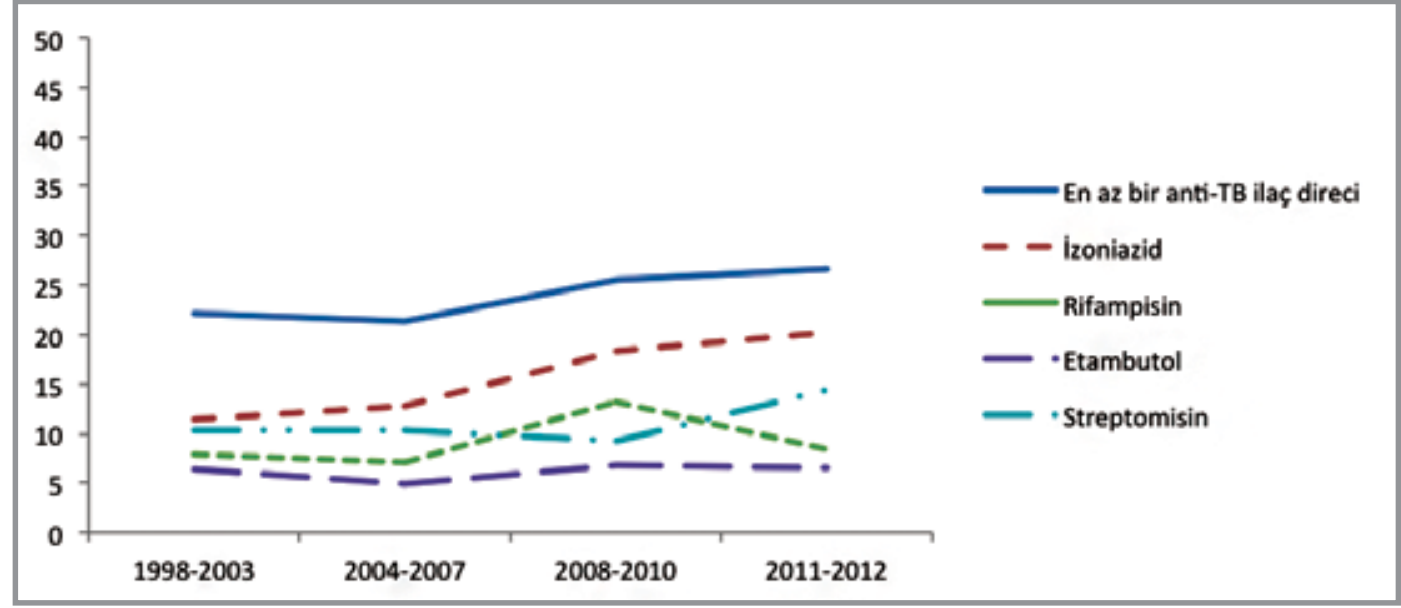

Şekil 2. Türkiye'den bildirilen çalışmaların sonuçlarına göre anti-tüberküloz ilaç direnç oranlarının yıllar içinde değişimi.

daha az etkili, toksisitesi yüksek ve pahalı ilaçların kullanılmasını gerektirir $(24,25)$. ÇiD-TB gelişen hastaların tedavi başarısı daha düşük ve mortalite oranı yüksektir $(1,26)$. Bu çalışmada, üçüncü seviyede bir TB laboratuvarında $M$. tuberkülosis kompleks izole edilen örneklerde birinci basamak anti-TB ilaçlara duyarlılık sonuçları yayınlanmıştır. Bulgularımıza göre 2011-2012 yıllarında herhangi bir anti-TB ilaca direnç oranı \%26.7'dir. En yüksek ilaç direnci $\mathrm{H}^{\prime}$ ye karşıdır. İlaç duyarlılığı çalışılan izolatların \%20.2'sinde, en az bir anti-TB ilaca dirençli izolatların 3/4'ünde $\mathrm{H}$ direnci vardır. Aynı merkezden daha önceki yıllarda yapılan çalışmalarda ilaç direnç oranı \%24.1 ve \%27.9 bulunmuştur $(6,7)$. DSÖ 2018 raporunda altı ülkede yapılan sürveyans çalışmalarında birinci basamak anti-TB ilaçlara direnç oranı yeni olgularda \%19 (\%95 Cl: \%18-20), önceden tedavi almış hastalarda \%43 (\%95 Cl: \%4046) olarak bildirmiştir (1). Türkiye'nin farklı bölgelerindeki TB laboratuvarlarından yayınlanmış araştırmalara göre herhangi bir anti-TB ilaca direnç oranı \%9.6-29 arasında olduğu görülmektedir (5-9,11-23).

$\mathrm{Bu}$ çalışmanın sonuçlarına göre $M$. tuberkülosis kompleks izole edilen izolatların \%7'sinde çiD-TB vardır. Bu oran Türkiye'den daha önce bildirilen hastane bazlı çalışmalardaki oranların ortalamasına benzerdir (4). Sağ lık Bakanlığı VSD raporunda bildirilen 2005-2016 oranlarından (\%3.3-5.4) yüksektir (2). Sağlık bakanlığı VSD 2018 verilerine göre Türkiye'de 2011-2012 yıllarında -bizim çalışmamızın yapıldığı dönem- ÇiD-TB oranı \%5.4 olarak bulunmuştur. Bu oran son 10 yılın en yüksek düzeyidir. Hem bizim hastanemizin 2008-2012 yılları arası verilerinde hem de Türkiye'nin farklı bölgelerinde yapılan hastane bazlı çalışmalarda ÇiD-TB oranının daha yüksek çıkması şaşırtıcı değildir. Çünkü Sağlık 
Bakanlığı verilerinin çoğunluğu VSD'leri kayıtlarına dayanmaktadır. Klinik çalışmaların yapıldığı üçüncü basamak hastaneler, dispanserlerde tedavi başarısızlığı gözlenen ve ilaç direnci ihtimali yüksek olan hastaların tedavi edildiği birimlerdir. Üçüncü basamak hastanelerde tedavi edilen hastaların ilaç direnç oranlarının VSD verilerinde yüksek olması bu şekilde açıklanabilir. Ayrıca, ilaç dirençlerini belirlemede kullanılan yöntemler farklı olabilir. Bizim hastanemizde duyarlılık testleri MGIT 960 sistemiyle düşük konsantrasyonlu tüplerde $(0.1 \mu \mathrm{g} / \mathrm{mL} \mathrm{H}, 1$ $\mu \mathrm{g} / \mathrm{mL}$ S) yapıımıştır. Sağlık Bakanlığı raporunda ilaç dirençlerinin nasıl çalışıldığı ve merkezler arasında fark olup olmadığı belirtilmemiştir. ÇiD-TB oranlarının düşük olmasının nedeni $\mathrm{H}$ için yüksek ilaç düzeyi $(0.4 \mu \mathrm{g} / \mathrm{mL})$ içeren tüplerde ilaç duyarlılık testleri yapılmasından kaynaklanıyor olabilir.

$\mathrm{Bu}$ çalışmada $\mathrm{H}$ direnç oranı \%20.2 saptanmıştır. Aynı merkezde daha önceki yıllarda yapılan incelemelerde de $\mathrm{H}$ direnç oranı yüksek bulunmuştur (\%18.9) $(6,7)$. Üçüncü basamak laboratuvarlarda yapılan diğer çalışmalarda $\mathrm{H}$ direnci \%6.1-21.6 arasında olduğu bildirilmiştir (5-9,11-23). Sağlık Bakanlığı raporuna göre 2011'de \%13.7, 2012'de $\% 15.4$ 'tür (2). Son yirmi yıldaki görünüme bakılırsa, Türkiye'de hastane bazlı çalışmalarda $\mathrm{H}$ direncinde yıllar içinde hafif miktarda artış, Sağlık Bakanlığı verilerine göre ise stabil bir seyir görülmektedir (Tablo 3, Şekil 2). DSÖ 2018 raporunda H direnç oranları -R direnci dışlanarak verilmiş- yeni TB olgularında \%7.1 (\%95 Cl: \%6.2-8.0), önceden tedavi alanlarda \%7.9 (\%95 Cl: \%5.9-10) olarak bildirilmiştir (1). Bu oran DSÖ tarafından 2008 için bildirilen \%5.9'luk orandan oldukça yüksektir. DSÖ verileri de $\mathrm{H}$ direncinin artmakta olduğunu göstermektedir (1).

Bu çalışmada dikkati çeken önemli bir bulgu S direncinin aynı hastaneden daha önce yapılan çalışmalar, Sağlık Bakanlığı ve DSÖ raporlarında bildirilenden yüksek olmasıdır (\%14.4). Türkiye'deki diğer üçüncü basamak hastanelerden yapılan çalışmalarda da benzer şekilde yüksek $S$ direnç oranları yayınlanmışıı (Tablo 3). Bu çalışmada S direncinin yüksek olmasının sebebi MGIT 960 duyarlılık test tüplerinde düşük ilaç konsantrasyonlu $(1 \mu \mathrm{g} / \mathrm{mL} \mathrm{S})$ tüplerin tercih edilmiş olması olabilir. Yüksek ilaç konsantrasyonlu (2 $\mu \mathrm{g} / \mathrm{mL}$ S) tüpler tercih edilmiş olsaydı oran daha düşük saptanabilirdi. Ayrıca, aynı laboratuvardan daha önce yayınlanan iki çalışmada, farklı bir kit (TK SLC) ile daha yüksek ilaç konsantrasyonlu (2 $\mu \mathrm{g} / \mathrm{mL}$ S) tüpler kullanılmasına rağmen bizim çalışmanın sonuçlarına benzer şekilde 2008 yılında S direnci yüksek bulunmuştur (6,7). Bu bulgular, $\mathrm{S}$ direnç oranlarının değişkenliğinde duyarlılık testi dışı faktörlerin de rolü olabileceğini göstermektedir. İlaç direnç oranları zaman içinde ve laboratuvardan laboratuvara büyük ölçüde değişkenlik gösterebilir. Streptomisin, bruselloz gibi TB dışı mikrobiyal etkenlerin tedavisinde de sıkça kullanılan bir antibiyotiktir. Streptomisine karşı direnç gelişiminde bruselloz için endemik bölgelerde TB dışı kullanımların rolü olabilir (27). Ancak, bu çalışmada $S$ direnci olan olguların büyük bir çoğunluğunun aynı zamanda diğer anti-TB ilaçlara dirençli olduğunu ( $n=97$, tüm $S$ dirençli olguların \%69.3'ü) gözden kaçırmamak gerekir.

Anti-TB ilaç direnç gelişmesinin risk faktörleri arasında önceden TB tedavisi almış olmak, latent TB için profilaksi amaçlı anti-TB ilaç kullanılması, yaş ve cinsiyet gösterilmiş, gençlerde ÇiD-TB düşük, orta yaşlarda yüksek olduğu iddia edilmiştir (6,24,28-30). Bu çalışmanın sonuçlarına göre yaş ve cinsiyet ile ilaç direnç oranları arasında ilişki saptanmamıştır.

Çalışmamızın bazı kısıtlılıkları vardır. Birincisi, hastaların klinik bilgileri yetersizdir. Çalışma grubumuzda yer alan hastalardan daha önce anti-TB ilaç kullananların sayısı ve oranı bilinmemektedir. İstanbul birçok milletten insanın yaşadığı bir metropoldür. Anti-TB ilaç direncinin fazla olduğu Asya kıtasından göç eden insanlar da i̇stanbul'da ikamet etmektedir. Bu çalışmada örnekleri incelenen hastaların ait olduğu millet, yaşadığı ve seyahat ettiği bölgeler ayrıntılı olarak bilinmemektedir. İincisi, ilaç duyarlılık testleri $(\mathrm{H}$ ve $\mathrm{S}$ için) düşük düzey ilaç direncini tespit eden tüplerle çalışıımıştır. Sonuçlarımızın bu faktörün de göz önünde bulundurularak değerlendirilmesi gerekir. Ayrıca, birinci basamak anti-TB ilaçlar içinde yer alan pirazinamid için duyarlılık testi çalışılmamıştır.

Sonuç olarak, bu çalışmada çok sayıda örneğin kabul edildiği bir TB laboratuvarının bir yıllık anti-TB ilaç duyarlılık test sonuçları sunulmuştur. Örneklerin çalışıldığı dönemdeki birinci basamak anti-TB ilaç direnç oranları hakkında önemli bilgiler elde edilmiştir. Aynı laboratuvarda ve Türkiye'nin diğer bölgelerinde daha önceki yıllarda yapılmış araştırmaların sonuçlarıyla birlikte değerlendirildiğinde $\mathrm{H}$ ve $\mathrm{S}$ direncinin yıllar içinde artma trendinde olduğu görülmektedir. Anti-TB ilaçlara direnç gelişimini etkileyen bölgesel ve global faktörleri araştıran ileri klinik çalışmalara ihtiyaç vardır. 


\section{ÇIKAR ÇATIŞMASI}

Yazarlar bu makale ile ilgili herhangi bir çıkar çatışması bildirmemişlerdir.

\section{YAZAR KATKISI}

Anafikir/Planlama: HY, DHC, SA

Analiz/Yorum: Tüm yazarlar

Veri sağlama: HY, DHC, LK

Yazım: HY, VY

Gözden Geçirme ve Düzeltme: HY, VY, SA

Onaylama: Tüm yazarlar

\section{KAYNAKLAR}

1. Global tuberculosis report 2018. Geneva: World Health Organization; 2018. Licence: CC BY-NC-SA 3.0 IGO. https://www.who.int/tb/publications/g/obal_report/en/

2. Türkiye'de Verem Savaşı Derneği 2018 Raporu T.C. Sağlık Bakanlı̆̆ı Halk Sağlığı Genel Müdürlügü̈. Ankara, 2018. https://hsgm.saglik.gov.tr/depo/birimler/tuberkulozdb/ dosyal raporlar /Tu_rkiye_de_Verem_Savas_ 2018_ Raporu_kapakl_.pdf

3. Petrini B, Hoffner $S$. Drug-resistant and multidrugresistant tubercle bacilli. Int I Antimicrob Agents 1999;13:93-7.

4. Uçar E, Kiliç A, Ceyhan I, Yilmaz S, Kiliç S, Tarhan G, et al. [Resistance rates to major anti-tuberculosis drugs in Mycobacterium tuberculosis strains isolated from seven different regions of Turkey in 2003-2006 period]. Mikrobiyol Bul 2010;44:11-9.

5. Sayğan MB, Ocak F, Cesur S, Tarhan G, Ceyhan I, Gümüişlü F, et al. Susceptibilities of Mycobacterium tuberculosis strains collected from regional tuberculosis laboratories to major antituberculous drugs. Mikrobiyol Bul 200741:403-9.

6. Yazar E, Yıldız P, Gunluoglu G, Altın S, Yilmaz V, Gencer D, et al. Drug Resistance Trends and Patterns of Mycobacterium Tuberculosis Isolates from Pulmonary Tuberculosis Patients at a Tertiary Care Hospital in Turkey. J Tuberc Res 2014;2:155-9.

7. Kocagöz T, Altın S, Türkyılmaz Ö, Taş $i$, Karaduman $P$, Bolaban D, et al. Efficiency of the TK Culture System in the diagnosis of tuberculosis. Diagn Microbiol Infect Dis 2012;72:350-7.

8. Baylan O, Albay A, Kisa O, Tekbaş OF, Deniz O. Detection of primary drug resistance rates of Mycobacterium tuberculosis complex strains isolated between 2002-2003 years and comparison with the data of 1998-2001 period. Mikrobiyol Bul 2005;39:153-60.

9. Cakir E, Erdem E, Ozlu N, Seber E, Gencer S, Kilicaslan Z. Demographic and microbial characteristics and drug resistance of childhood tuberculosis in Istanbul: analysis of 1.541 cases. I Infect Dev Ctries 2014;8:304-9.
10. Rüsch-Gerdes S, Domehl C, Nardi G, Gismondo MR, Welscher HM, Pfyffer GE. Multicenter evaluation of the Mycobacteria growth indicator tube for testing susceptibility of Mycobacterium tuberculosis to first-line drugs. J Clin Microbiol 1999;37:45-8.

11. Karagoz T, Pazarli P, Mocin OY, Duman D, Duman G, Salturk $C$, et al. Evaluation of drug resistance in pulmonary tuberculosis patients at Sureyyapasa Chest Diseases Hospital, Istanbul, Turkey. Int I Tuberc Lung Dis 2008; 12:631-5.

12. Tatar D, Senol G, Cosar D, Ozacar R, Halilcolar H. Patterns of drug resistance in pulmonary tuberculosis cases in the Izmir district, Turkey. New Microbiol 2009;32:31-7.

13. Pazarli P, Karagoz T, Yaziciog/u Mocin O, Duman D, Akel G. Drug resistance in pulmonary tuberculosis in Turkey. Eur I Clin Microbiol Infect Dis 2007;26:431-3.

14. Bilgin S, Unsal M, Cebi HH, Akgunes A. Resistance for anti-tuberculosis drugs in central Black Sea region of Turkey. Pol J Microbiol 2010;59:125-8.

15. Komurcuoglu B, Senol G, Balci G, Yalnız E, Ozden E. Drug resistance in pulmonary tuberculosis in new and previously treated cases: experience from Turkey. I Infect Public Health 2013;6:276-82.

16. Tanrikulu AC, Hosoglu S, Ozekinci T, Abakay A, Gurkan F. Risk factors for drug resistant tuberculosis in southeast Turkey. Trop Doct 2008;38:91-3.

17. Aydın F, Kaklıkkaya N, Bayramoğlu G, Ozkul G, Buruk K, Dinç $U$, et al. Resistance rates of Mycobacterium tuberculosis complex strains isolated from clinical specimens. Mikrobiyol Bul 2011;45:36-42.

18. Agarwal M, Gunal S, Durmaz R, Yang Z. Integration of Mycobacterium tuberculosis drug susceptibility testing and genotyping with epidemiological data analysis to gain insight into the epidemiology of drug-resistant tuberculosis in Malatya, Turkey. J Clin Microbiol 2010;48:3301-5.

19. Surucuoglu S, Ozkutuk N, Celik P, Gazi H, Dinc G, Kurutepe $S$, et al. Drug-resistant pulmonary tuberculosis in western Turkey: prevalence, clinical characteristics and treatment outcome. Ann Saudi Med 2005;25:313-8.

20. Sengul A, Akturk UA, Aydemir Y, Kaya N, Kocak ND, Tasolar FT. Factors affecting successful treatment outcomes in pulmonary tuberculosis: a single-center experience in Turkey, 2005-2011. J Infect Dev Ctries 2015;9:821-8.

21. Gönlügür $U$, Bakici $M Z$, Gönlügür $T E$, Hasbek $M$. [Resistance rates to antituberculous drugs in Sivas province]. Mikrobiyol Bul 2007;41:459-63.

22. Sezen F, Albayrak N, Özkara Ş, Karagöz A, Alp A, Duyar Ağca $F$ ve ark. Laboratuvar Sürveyans Ağı Tulsa Çalısma Grubu, Tulsa Tuberculosis Laboratory Surveillance Network (TuLSA) study group. The first step for national tuberculosis laboratory surveillance: Ankara, 2011. Mikrobiyol Bul 2015;49:143-55. 
23. Senbayrak S, Ozkutuk N, Erdem H, Johansen IS, Civljak R, Inal AS, et al. Antituberculosis drug resistance patterns in adults with tuberculous meningitis: results of haydarpasaiv study. Ann Clin Microbiol Antimicrob 2015;14:47.

24. Frieden TR, Sterling TR, Munsiff SS, Watt CJ, Dye C. Tuberculosis. Lancet 2003;13:887-99.

25. Pillay $M$, Sturm AW. Evolution of the extensively drugresistant F15/LAM4/KZN strain of Mycobacterium tuberculosis in KwaZulu-Natal, South Africa. Clinical Infectious Diseases 2007;45:1409-14.

26. Ismail N, Ismail F, Omar SV, Blows L, Gardee Y, Koornhof $H$, et al. Drug resistant tuberculosis in Africa: Current status, gaps and opportunities. Afr J Lab Med 2018;7:781.

27. Al-Hajjaj MS, Al-Kassimi FA, Al-Mobeireek AF, Alzeer AH. Progressive rise of Mycobacterium tuberculosis resistance to rifampicin and streptomycin in Riyadh, Saudi Arabia. Respirology 2001;6:317-22.
28. Shamaei M, Marjani M, Chitsaz E, Kazempour M, Esmaeili $M$, Farnia $P$, et al. First-line anti-tuberculosis drug resistance patterns and trends at the national TB referral center in Iran--eight years of surveillance. Int I Infect Dis 2009; 13:e236-40.

29. Quy HT, Buu TN, Cobelens FG, Lan NT, Lambregts CS, Borgdorff MW. Drug resistance among smear-positive tuberculosis patients in Ho Chi Minh City, Vietnam. Int I Tuberc Lung Dis 2006;10:160-6.

30. Ocheretina $O$, Morose $W$, Gauthier M, Joseph P, D'Meza $R$, Escuyer VE, et al. Multidrug-resistant tuberculosis in Port-au-Prince, Haiti. Rev Panam Salud Publica 2012;31:221-4. 